\title{
Preoperative cigarette smoking and short-term morbidity and mortality after cardiac surgery: a meta- analysis
}

\author{
Nicholas Gregory Ross Bayfield, ${ }^{1}$ Adrian Pannekoek, ${ }^{1}$ David Hao Tian ${ }^{2}$
}

- Additional material is published online only. To view please visit the journal online (http://dx.doi.org/10.1136/ heartasia-2018-011069).

${ }^{1}$ Department of Clinical Services, Fiona Stanley Hospital, Perth, Australia

${ }^{2}$ Collaborative Research (CORE) Group, Macquarie University, Sydney, Australia

\section{Correspondence to} Dr Nicholas Gregory Ross Bayfield, Department of Clinical Services, Fiona Stanley Hospital, Murdoch WA 6150, Australia; Nicholas.Bayfield@health.wa. gov.au

Received 15 May 2018 Revised 7 September 2018 Accepted 2 October 2018

\section{Check for updates}

(C) Author(s) (or their employer(s)) 2018. No commercial re-use. See rights and permissions. Published by BMJ.

To cite: Bayfield NGR, Pannekoek A, Tian DH. Heart Asia 2018:10:e011069. doi:10.1136/

heartasia-2018-011069

\section{ABSTRACT}

Currently, the choice of whether or not to electively operate on current smokers is varied among cardiothoracic surgeons. This meta-analysis aims to determine whether preoperative current versus exsmoking status is related to short-term postoperative morbidity and mortality in cardiac surgical patients. Systematic literature searches of the PubMed, MEDLINE and Cochrane databases were carried out to identify all studies in cardiac surgery that investigated the relationship between smoking status and postoperative outcomes. Extracted data were analysed by random effects models. Primary outcomes included 30-day or in-hospital all-cause mortality and pulmonary morbidity. Overall, 13 relevant studies were identified, with 34230 patients in current or ex-smoking subgroups. There was no difference in mortality $(p=0.93)$. Current smokers had significantly higher risk of overall pulmonary complications (OR 1.44; 95\% Cl 1.27 to $1.64 ; \mathrm{p}<0.001$ ) and postoperative pneumonia (OR 1.62; 95\% Cl 1.27 to $2.06 ; p<0.001)$ as well as lower risk of postoperative renal complications (OR 0.82; $95 \% \mathrm{Cl} 0.70$ to 0.96 ; $\mathrm{p}=0.01$ ) compared with ex-smokers. There was a trend towards an increased risk of postoperative MI (OR 1.29; $95 \% \mathrm{Cl} 0.95$ to 1.75; $p=0.10)$. No difference in postoperative neurological complications $(p=0.15)$, postoperative sternal surgical site infections $(p=0.20)$ or postoperative length of intensive care unit stay $(p=0.86)$ was seen. Cardiac surgical patients who are current smokers at the time of operation do not have an increased 30-day mortality risk compared with exsmokers, although they are at significantly increased risk of postoperative pulmonary complications.

\section{INTRODUCTION}

Variations exist between cardiothoracic surgeons as to willingness to electively operate on existing smokers. Current cigarette smoking status is thought to be related to perioperative morbidity in a number of surgical fields, most particularly in cardiac surgery. While past retrospective cohort studies in cardiac surgical patients have explored the relationship between current smoking status and perioperative morbidity and mortality, ${ }^{1-5}$ there is conflicting evidence regarding a number of perioperative complications such as postoperative myocardial infarction (MI), ${ }^{16}$ surgical site infections $(\mathrm{SSI})^{78}$ and prolonged postoperative intensive care unit (ICU) stay, ${ }^{14-11}$ with no comprehensive systematic reviews or meta-analysis on the subject available. Furthermore, there is a lack of evidence directly comparing current smokers with ex-smokers, and fewer still that compare current smokers with recent (within 12 months of operation) ex-smokers.

Recent evidence suggests that perioperative smoking cessation is often successful, ${ }^{12}$ and thus surgical teams should have a firm understanding of the benefits of preoperative smoking cessation to improve outcomes. The present meta-analysis evaluates whether preoperative smoking status (current vs ex-smokers) influences short-term postoperative morbidity and mortality outcomes in adult cardiac surgery.

\section{METHODS}

\section{Literature search strategy}

Electronic searches were performed on PubMed, MEDLINE and the Cochrane Library (Cochrane Database of Systematic Reviews and Cochrane Central Register of Controlled Trials) from inception through August 2017 for relevant studies. A broad search strategy was developed after reviewing similar searches in related literature. To maximise the initial scope of the search, 'smoking AND ((thoracic surgery) OR (thoracic AND surgery) OR (cardiac surgery) OR (cardiac AND surgery) OR (coronary artery bypass))' was used as the search strategy. All records were systematically assessed using established inclusion and exclusion criteria. References of included studies were manually assessed for possible inclusion in the present review. Two researchers independently conducted an initial search, and any discrepancies in inclusions were resolved by discussion and mutual agreement.

A Preferred Reporting Items for Systematic Reviews and Meta-Analyses flowchart of the literature search strategy of studies investigating the impact of smoking status at the time of cardiac surgery is presented in the online supplementary file 1 .

\section{Selection criteria}

Primary inclusion criteria were any observational or interventional study of adult cardiac surgery patients that presented short-term postoperative mortality or complication data and presented sub-group analysis of outcomes for ex-smokers and current smokers. Current smoking was defined as smoking at least one cigarette per day within 1 week of the date of operation, and ex-smokers were defined as patients who had ceased smoking over 1 week prior to the date of operation. The primary outcomes were defined as 30-day or in-hospital all-cause mortality and overall postoperative pulmonary complications (including pneumonia, 
clinically significant atelectasis, prolonged mechanical ventilation, ARDS, pneumothorax and pleural effusion requiring drainage). Secondary outcomes were defined as postoperative pneumonia (in isolation), postoperative myocardial infarction, postoperative neurological event (stroke or TIA), new postoperative renal failure or dialysis requirement, sternal wound infection (superficial or deep) and length of postoperative ICU stay. The definition of ex-smoking status for each source study was recorded.

\section{Quality assessment}

Included studies were screened for quality with a Quality Assessment Tool for Observational Cohort and Cross-Sectional Studies. ${ }^{13}$ A numerical checklist of criteria was used to assist with judgement of study quality. Each study was scored from 1 to 14 based on the criteria, and the numerical scores were assessed for outliers. Studies were rated 'good' (10-14 points), 'fair' (7-9) or 'poor' $(<7)$. Quality assessment was performed independently by two reviewers.

\section{Statistical analysis}

Patient demographic data for ex-smokers and current smoker groups were extracted from each study, as well as postoperative outcomes. Baseline demographics were pooled as meta-analysis of proportions or means as appropriate. For each dichotomous postoperative complication, a random effect model was used to generate a Mantel-Haenszel OR, as a high chance of statistical heterogeneity was assumed. For the analysis of the continuous data of length of intensive care stay, a random effect model was used to generate a mean difference (in hours) with the inverse variance statistical method. Statistical heterogeneity was assessed using the $\mathrm{I}^{2}$ statistic. Publication bias was tested for in both primary outcomes using funnel plots and Egger's linear regression method. Subgroup analysis was performed on studies which defined current smoking as any smoking within 4 weeks of operation and coronary artery bypass grafting-only studies. Further subgroup analysis was performed on the primary endpoints in studies rated 'good' as a sensitivity analysis. The median year of patient recruitment was assessed in meta-regression to determine temporal influences on the heterogeneity on overall pulmonary complications. Data were analysed with Review Manager (V.5.3, Cochrane Collaboration, Software Update, Oxford, UK) and Comprehensive Meta-Analysis Software (V.3, Biostat, Englewood, USA).

\section{RESULTS}

\section{Literature search}

Overall, 5805 records were identified in the literature search. Following application of the inclusion and exclusion criteria, 17 studies were deemed suitable for inclusion in the systematic review, of which 13 were quantitatively analysed. ${ }^{1-6}{ }^{14-20}$ Four studies were analysed qualitatively due to incompatible data presentation or data presentation that was not able to be reconciled into statistical analysis; results from all of these studies were in concordance with our meta-analytical findings. ${ }^{21-24}$ The characteristics of the included studies are summarised in table 1.

Thirteen studies were eligible for inclusion in the statistical meta-analysis. Of these, eight investigated mortality. ${ }^{1-61519}$ Ten investigated overall pulmonary complications, ${ }^{-4614151819}$ and six specifically investigated pneumonia. ${ }^{1-3} 51819$ Five studies investigated postop MI. ${ }^{1-36}{ }^{19}$ Seven studies investigated renal complications. $^{1-6} \quad 15$ Eight studies investigated neurological complications. $^{1-6} 1519$ Eight studies investigated a variety of sternal wound complications. ${ }^{1-3561618-20}$ Seven studies reported mean length of ICU stay with CIs. ${ }^{1-461517}$

Seven studies defined current smokers as smoking within 4 weeks of operation. Four studies did not define the time period of smoking cessation prior to operative date that they used to classify ex-smokers. ${ }^{14161920}$ Guan et al $^{17}$ included a robust stratification of patients into sustained quitters (quit 1 month-1 year preop), recent quitters (quit 1 month-1 week preop) and current smokers.

\section{Quality assessment}

Quantitatively, studies ranged from 8 to 11 points out of the possible maximum 14 points. There were no significant outliers. Significant variations existed as to the sample sizes and the

Table 1 Study characteristics

\begin{tabular}{|c|c|c|c|c|c|c|}
\hline Lead author & Year & Type of study & Included surgeries & Location & Current smoking status definition & $\begin{array}{l}\text { Quality score and } \\
\text { rating (if in meta- } \\
\text { analysis) }\end{array}$ \\
\hline Ngaage et $a l^{18}$ & 2002 & Retrospective cohort study & All elective cardiac surgeries & UK, single centre & $<3$ month preop smoking & 11, Good \\
\hline Saxena et $a l^{2}$ & 2013 & Retrospective cohort study & AVR & Australia, multi-centre & $<1$ month preop smoking & 11, Good \\
\hline Saxena et $a l^{3}$ & 2014 & Retrospective cohort study & $A V R+C A B G$, concomitant & Australia, multi-centre & $<1$ month preop smoking & 11, Good \\
\hline Ji et $a l^{6}$ & 2015 & Retrospective cohort study & CABG & China, single centre & $<1$ month preop smoking & 10, Good \\
\hline Al-Sarraf et al ${ }^{4}$ & 2008 & Retrospective cohort study & CABG & Kuwait, single centre & $<4$ weeks preop smoking & 11, Good \\
\hline Al-Sarraf et $a l^{15}$ & 2007 & Retrospective cohort study & All valvular surgeries & Kuwait, single centre & $<4$ weeks preop smoking & 11, Good \\
\hline Shih et $a l^{21}$ & 2014 & Retrospective cohort study & All cardiac surgeries & USA, multi-centre & $<2$ weeks preop smoking & - \\
\hline Guan et $a l^{17}$ & 2016 & Prospective cohort study & On-pump CABG & China, single centre & $<1$ week preop smoking & 9, Fair \\
\hline Warner et a $\left.\right|^{23}$ & 1984 & Retrospective cohort study & CABG & USA, single centre & Smoking up to date of operation & - \\
\hline Mortasawi et a l $^{19}$ & 2004 & Retrospective cohort study & CABG & UK, single centre & Current versus ex (no time specified) & 10, Good \\
\hline Harrington et $a l^{22}$ & 2004 & Prospective cohort study & CABG & Australia, multicentre & Current versus ex (no time specified) & - \\
\hline Warner et $a l^{24}$ & 1989 & Prospective cohort study & CABG & USA, single centre & Urinary cotinine $<0.5 \mathrm{ug} / \mathrm{mL}$ & - \\
\hline
\end{tabular}

$A V R$, aortic valve replacement; $C A B G$, coronary artery bypass grafting. 
Table 2 Baseline characteristics

\begin{tabular}{|c|c|c|c|}
\hline & Current smokers & Ex-smokers & $\begin{array}{l}\text { Number of patients (studies) for } \\
\text { which data were retrievable }\end{array}$ \\
\hline Total & 8402 & 25828 & $34230(13)$ \\
\hline Age (mean $\pm S D$, years) & $65.5 \pm 1.6$ & $60.9 \pm 1.5$ & $22079(7)$ \\
\hline Female (\%) $(95 \% \mathrm{Cl})$ & $11.8(5.3$ to 24.4$)$ & $11.4(6.4$ to 19.6$)$ & $14397(6)$ \\
\hline Preoperative hypertension (\%) $(95 \% \mathrm{Cl})$ & 60.0 (49.1 to 70.0$)$ & 63.3 (52.9 to 72.6$)$ & $22079(7)$ \\
\hline Preoperative hypercholesterolaemia (\%) $(95 \% \mathrm{Cl})$ & 50.1 (22.9 to 77.3$)$ & 57.5 (36.3 to 76.2$)$ & $19940(5)$ \\
\hline Preoperative left main disease $(\%)(95 \% \mathrm{Cl})$ & 23.5 (20.8 to 26.3$)$ & $21.6(17.8$ to 26.0$)$ & $26918(5)$ \\
\hline Preoperative congestive heart failure (\%) $(95 \% \mathrm{Cl})$ & 23.3 (12.6 to 38.9$)$ & $24.0(13.3$ to 39.4$)$ & $21703(5)$ \\
\hline Preoperative $\mathrm{PHx}$ of $\mathrm{Ml}$ or recent $\mathrm{MI}(\%)(95 \% \mathrm{Cl})$ & 28.5 (18.4 to 41.2$)$ & $18.6(10.7$ to 30.3$)$ & $23889(6)$ \\
\hline Preoperative diabetes mellitus (\%) $95 \% \mathrm{Cl}$ ) & 20.6 (15.8 to 26.5$)$ & 23.8 (18.9 to 29.5$)$ & $28993(8)$ \\
\hline Preoperative peripheral vascular disease $(\%)(95 \% \mathrm{Cl})$ & $13.4(10.7$ to 16.8$)$ & $12.0(9.7$ to 14.7$)$ & $26507(6)$ \\
\hline Preoperative PHx of CVA/CVD (\%) $(95 \% \mathrm{Cl})$ & 9.9 (7.0 to 13.9$)$ & $12.8(9.2$ to 17.5$)$ & $23552(5)$ \\
\hline Preoperative COPD (\%) (95\% Cl) & 17.6 (11.6 to 25.9$)$ & 14.6 (9.7 to 21.3$)$ & $30532(8)$ \\
\hline Preoperative renal failure (\%) $(95 \% \mathrm{Cl})$ & 2.6 (2.0 to 3.4$)$ & $3.3(2.7$ to 4.0$)$ & $26170(5)$ \\
\hline Cardiopulmonary bypass time (mean $\pm S D$, min) & $102.5 \pm 5.2$ & $97.0 \pm 8.9$ & $20240(6)$ \\
\hline Cross clamp time (mean $\pm \mathrm{SD}$, min) & $81.0 \pm 5.2$ & $78.6 \pm 8.5$ & $19940(5)$ \\
\hline
\end{tabular}

COPD, chronic obstructive pulmonary disease; CVA, cerebrovascular accident; CVD, cardiovascular disease; Ml, myocardial infarction; Phx, past history.

classification of ex-smokers according to the period of smoking cessation. Studies with higher scores had a larger group of subjects and a more robust stratification of smoking status. There were overall low rates of incomplete data impacting on inclusion rate of patients. There was no clear reason that would bias the researchers in one way or another. Classifications of postoperative complications were well-defined across studies. All studies were rated either 'good' or 'fair' and thus judged suitable for inclusion in the meta-analysis. There were no disagreements in classification of 'good/fair' between the two researchers. Quantitative scores and good/fair ratings are presented in table 1.

\section{Clinical outcomes}

Overall, 34230 patients were included in the statistical meta-analysis. There was no overlap between studies. Baseline data are presented in table 2.

Current smokers were shown to have a significantly increased risk in postoperative overall pulmonary complications (OR $1.44 ; 95 \%$ CI 1.27 to $\left.1.64 ; \mathrm{p}<0.001, \mathrm{I}^{2}=45 \%\right)$ and in postoperative pneumonia (OR 1.62; 95\% CI 1.27 to 2.06 ; $\mathrm{p}<0.001$, $\left.\mathrm{I}^{2}=67 \%\right)$ compared with ex-smokers. There was a trend towards an increased risk in postoperative MI (OR 1.29; 95\% CI 0.95 to $1.75 ; \mathrm{p}=0.10, \mathrm{I}^{2}=18 \%$ ) for current smokers. There was no difference in mortality $(p=0.93)$, postoperative neurological complications $(\mathrm{p}=0.15)$ or postoperative sternal surgical site infections $(p=0.20)$. Current smokers were shown to have a statistically significant decrease in risk of postoperative renal complications (OR $0.82 ; 95 \%$ CI 0.70 to $0.96 ; \mathrm{p}=0.01, \mathrm{I}^{2}=0 \%$ ). There was no difference in postoperative length of ICU stay $(p=0.86)$. Statistical outcomes are presented in table 3 . Forest plots of primary and secondary outcomes presented in the online supplementary files 2-9.

Subgroup analysis did not change the significance or effect of any results. Meta-regression identified the median year of patient recruitment as a significant influence on the heterogeneity of the results for postoperative pulmonary complications $\left(\beta=-0.05, p<0.001, R^{2}=1.0\right)$, suggesting that increased risk for current smokers has reduced in recent years. Egger's linear regression test did not identify any publication bias on assessment of both primary outcomes (two-tailed $p=0.20$ and $p=0.52$, respectively), although the small amount of studies may limit the sensitivity of the test. Forest plots of subgroup analysis are presented in the online supplementary files 10-12. Funnel plots are presented in the online supplementary files $13 ; 14$

\section{DISCUSSION}

The present meta-analysis found that there is no tangible relationship between current smoking status and short-term mortality after cardiac surgery, as consistent with data from other surgical specialties. ${ }^{9}$ However, other studies have shown that continued smoking results in increased mortality from 1 year postoperatively through to long-term outcomes ${ }^{25-28}$ and that postoperative smoking cessation improves life expectancy. ${ }^{29}$ Thus, while there is no clear evidence of mortality benefit in the perioperative period, smoking cessation is certainly a desirable long-term goal. A preoperative approach to initiating smoking cessation should be considered, as recent evidence suggests that preoperative smoking cessation is often successful and may have an improved success rate with interventions. ${ }^{12}$ The period prior to cardiac surgery is a time that lends itself towards educating patients on the harms of smoking, especially as the relationship between smoking and cardiovascular disease is not apparent to many patients. ${ }^{30}$

The pathophysiology of smoking and its effect on the lungs is well known. Cigarette smoking accelerates lung function decline over time, ${ }^{31}$ and inflammatory effects on the small

Table 3 Clinical outcomes for current smokers and ex-smokers undergoing cardiac surgery

\begin{tabular}{llrl} 
& OR $(95 \% \mathrm{CI})$ & $\mathrm{I}^{2}$ & P values \\
\hline Mortality & $0.99(0.78$ to 1.25$)$ & $18 \%$ & 0.93 \\
Pulmonary complications & $1.44(1.27$ to 1.64$)$ & $45 \%$ & $<0.00001$ \\
Pneumonia & $1.62(1.27$ to 2.06$)$ & $67 \%$ & $<0.0001$ \\
Renal complications & $0.82(0.70$ to 0.96$)$ & $0 \%$ & 0.01 \\
Myocardial infarction & $1.29(0.95$ to 1.75$)$ & $18 \%$ & 0.1 \\
Neurological complications & $1.19(0.94$ to 1.52$)$ & $15 \%$ & 0.15 \\
Surgical site infections & $1.14(0.94$ to 1.38$)$ & $0 \%$ & 0.2 \\
\hline Intensive care unit length of stay & $0.19 *(-2.01$ to 2.40$)$ & $63 \%$ & 0.86 \\
\hline
\end{tabular}

*Mean difference. 
airways increase the susceptibility of the lungs to respiratory complications such as infection and atelectasis. ${ }^{18}$ Postoperative pulmonary complications thus are an unsurprising outcome postcardiac surgery, and the present review subsequently shows that the odds of developing such complications in current smokers was increased by $44 \%$. Postoperative pneumonia is the most common infection following open-heart surgery and is a major cause of perioperative morbidity and mortality. ${ }^{32}$ Taking reasonable measures to reduce the risk of postoperative pneumonia is a desirable perioperative goal, and advocating preoperative smoking cessation seems justifiable to reduce the risk of these complications.

There is conjecture over where smoking cessation within 6-8 weeks of surgery may increase risk of pulmonary complications in the perioperative period ${ }^{10}$ and calls for further research in this area. ${ }^{9}$ This conjecture is related to a known transient increase in sputum production within the first $6-8$ weeks of smoking cessation. ${ }^{33}$ The stratification of smokers in the studies contributing to this meta-analysis was inadequate to investigate the possibility of this effect. In future studies, more robust stratification of smokers should be considered. Furthermore, there is a paucity of evidence exploring the effects of smoking cessation $0-4$ weeks preoperatively. The results of this meta-analysis are most valid when applied to patients who ceased smoking $<1$ month preoperatively, as these patients constitute the vast majority of the sample size.

Smoking is also a known significant contributor to cardiovascular disease, with long-term effects of atherosclerosis, ${ }^{34}$ hypertension ${ }^{35}$ and direct myocardial remodelling. ${ }^{36}$ It has unfavourable effects directly on the coronary endothelium, causing coronary arterial vasoconstriction and increased myocardial oxygen demand. ${ }^{37}$ However, the included studies herein have invariably failed to find a significant rate of postoperative MI in current smokers. The results of this meta-analysis show a non-significant trend towards an increased risk of postop MI in current smokers; however, only five studies presented postoperative MI data. Further studies may be beneficial in exploration of this result.

An unexpected result of this meta-analysis was the association between preoperative smoking cessation and an increased risk of renal complications postoperatively. This is a counter-intuitive result, as smoking overall is a known risk factor for both chronic kidney disease ${ }^{38}$ and postoperative acute kidney injury, ${ }^{39} 40$ although these studies did compare non-smokers to current smokers. This result may be due to some confounding variable that was unable to be controlled for herein, or there may be some true underlying effect. Further research should be directed at exploring this result.

There are several limitations to the present study that must be considered when interpreting the findings. First, there were no stratifications in the data set to account for pack-year history in either ex-smokers or current smokers. Smoking status was assessed primarily by history and confirmation of ex-smoking status in particular is difficult. In all but one study, the ex-smoking groups were not differentiated by the duration prior to surgery when the patients quit. In future studies, more robust analysis incorporating the time frames of smoking cessation will allow for closer analysis of the effects of smoking cessation prior to surgery.

The results of this meta-analysis are clinically significant in reinforcing the significant pulmonary morbidity associated with current cigarette smoking at the time of cardiac surgery. Clinical urgency of need for elective open-heart surgery should be counterbalanced against the pulmonary morbidity associated with operating on current smokers and consideration given to aiming for a significant preoperative period of smoking abstinence.

In conclusion, cardiac surgical patients who are current smokers at the time of operation do not have an increased mortality risk compared with ex-smokers, although they are at significantly increased risk of postoperative pulmonary complications including pneumonia. There is no difference in postoperative ICU admission length between current and ex-smokers. With known impact on long-term mortality, smoking cessation should continue to be encouraged at all points. Pulmonary morbidity outcomes justify a decision to be cautious of electively operating on current smokers.

Contributors NGRB and DHT contributed to the conception or design of the work. All authors contributed to the data collection, data analysis and interpretation, drafting the article, critical revision of the article and final approval of the version to be published.

Funding The authors have not declared a specific grant for this research from any funding agency in the public, commercial or not-for-profit sectors.

Competing interests None declared.

Patient consent Not required.

Provenance and peer review Not commissioned; externally peer reviewed.

Data sharing statement Raw data used to perform statistical analysis will be available by directly contacting the corresponding author and requesting it. However, as this data is synthesised from a series of studies included in the meta-analysis, all of this data is already available online in the text of each respective article.

\section{REFERENCES}

1 Saxena A, Shan L, Reid C, et al. Impact of smoking status on early and late outcomes after isolated coronary artery bypass graft surgery. J Cardiol 2013;61:336-41.

2 Saxena A, Shan L, Dinh DT, et al. Impact of smoking status on early and late outcomes after isolated aortic valve replacement surgery. J Heart Valve Dis 2013;22:184-91.

3 Saxena A, Shan L, Dinh DT, et al. Impact of smoking status on outcomes after concomitant aortic valve replacement and coronary artery bypass graft surgery. Thorac Cardiovasc Surg 2014;62:052-9.

4 Al-Sarraf N, Thalib L, Hughes A, et al. Effect of smoking on short-term outcome of patients undergoing coronary artery bypass surgery. Ann Thorac Surg 2008;86:517-23.

5 Benedetto $\mathrm{U}$, Albanese A, Kattach $\mathrm{H}$, et al. Smoking cessation before coronary artery bypass grafting improves operative outcomes. J Thorac Cardiovasc Surg 2014;148:468-74.

6 Ji Q, Zhao H, Mei Y, et al. Impact of smoking on early clinical outcomes in patients undergoing coronary artery bypass grafting surgery. J Cardiothorac Surg 2015;10:16.

7 Salehi Omran A, Karimi A, Ahmadi SH, et al. Superficial and deep sternal wound infection after more than 9000 coronary artery bypass graft (CABG): incidence, risk factors and mortality. BMC Infect Dis 2007;7:112.

8 Sharif-Kashani B, Shahabi P, Mandegar MH, et al. Smoking and wound complications after coronary artery bypass grafting. J Surg Res 2016;200:743-8.

9 Theadom A, Cropley M. Effects of preoperative smoking cessation on the incidence and risk of intraoperative and postoperative complications in adult smokers: a systematic review. Tob Control 2006;15:352-8.

10 Moores LK. Smoking and postoperative pulmonary complications. An evidence-based review of the recent literature. Clin Chest Med 2000;21:139-46.

11 Moore S, Mills BB, Moore RD, et al. Perisurgical smoking cessation and reduction of postoperative complications. Am J Obstet Gynecol 2005;192:1718-21.

12 Prestwich A, Moore S, Kotze A, et al. How can smoking cessation be induced before surgery? A systematic review and meta-analysis of behavior change techniques and other intervention characteristics. Front Psychol 2017;8:915.

13 NHLBI N, 2014. Quality assessment tool for observational cohort and cross-sectional studies. Nhlbi.nih.gov

14 Siddiqui MM, Paras I, Jalal A. Risk factors of prolonged mechanical ventilation following open heart surgery: what has changed over the last decade? Cardiovasc Diagn Ther 2012;2:192-9.

15 Al-Sarraf N, Thalib L, Hughes A, et al. Lack of correlation between smoking status and early postoperative outcome following valve surgery. Thorac Cardiovasc Surg 2008;56:449-55.

16 Olsen MA, Lock-Buckley P, Hopkins D, et al. The risk factors for deep and superficial chest surgical-site infections after coronary artery bypass graft surgery are different. J Thorac Cardiovasc Surg 2002;124:136-45. 
17 Guan Z, Lv Y, Liu J, et al. Smoking cessation can reduce the incidence of postoperative hypoxemia after on-pump coronary artery bypass grafting surgery. J Cardiothorac Vasc Anesth 2016;30:1545-9.

18 Ngaage DL, Martins E, Orkell E, et al. The impact of the duration of mechanical ventilation on the respiratory outcome in smokers undergoing cardiac surgery. Cardiovasc Surg 2002;10:345-50.

19 Mortasawi A, Ashraf MN, Grayson AD, et al. Impact of smoking on the results of coronary artery bypass surgery. Herz 2004;29:310-6.

20 Nagachinta T, Stephens M, Reitz B, et al. Risk factors for surgical-wound infection following cardiac surgery. J Infect Dis 1987;156:967-73.

21 Shih T, Paone G, Theurer PF, et al. the society of thoracic surgeons adult cardiac surgery database version 2.73: more is better. Ann Thorac Surg 2015;100:516-21.

22 Harrington G, Russo P, Spelman D, et al. Surgical-site infection rates and risk factor analysis in coronary artery bypass graft surgery. Infect Control Hosp Epidemiol 2004:25:472-6.

23 Warner MA, Divertie MB, Tinker JH. Preoperative cessation of smoking and pulmonary complications in coronary artery bypass patients. Anesthesiology 1984;60:380-3.

24 Warner MA, Offord KP, Warner ME, et al. Role of preoperative cessation of smoking and other factors in postoperative pulmonary complications: a blinded prospective study of coronary artery bypass patients. Mayo Clin Proc 1989;64:609-16.

25 Lindsay GM, Tolmie EP, Martin WM, et al. Smoking after coronary artery bypass: high three-year mortality. Thorac Cardiovasc Surg 2009;57:135-40.

26 Zhang YJ, Iqbal J, van Klaveren D, et al. Smoking is associated with adverse clinical outcomes in patients undergoing revascularization with $\mathrm{PCI}$ or CABG: the SYNTAX trial at 5-year follow-up. J Am Coll Cardiol 2015;65:1107-15.

27 Herlitz J, Haglid M, Albertsson P, et al. Short- and long-term prognosis after coronary artery bypass grafting in relation to smoking habits. Cardiology 1997;88:492-7.

28 Voors AA, van Brussel BL, Plokker HW, et al. Smoking and cardiac events after venous coronary bypass surgery. A 15-year follow-up study. Circulation 1996;93:42-7.

29 van Domburg RT, op Reimer WS, Hoeks SE, et al. Three life-years gained from smoking cessation after coronary artery bypass surgery: a 30-year follow-up study. Am Heart $J$ 2008:156:473-6.
30 Gabriel M, Noyez L, Verheugt FW, et al. Smoking behaviour of patients undergoing cardiac surgery. Neth Heart J 2002;10:229-34.

31 Walters MS, De BP, Salit J, et al. Smoking accelerates aging of the small airway epithelium. Respir Res 2014;15:94.

32 Allou N, Allyn J, Snauwaert A, et al. Postoperative pneumonia following cardiac surgery in non-ventilated patients versus mechanically ventilated patients: is there any difference? Crit Care 2015;19:116

33 Yamashita S, Yamaguchi H, Sakaguchi M, et al. Effect of smoking on intraoperative sputum and postoperative pulmonary complication in minor surgical patients. Respir Med 2004;98:760-6.

34 Howard G, Wagenknecht LE, Burke GL, et al. Cigarette smoking and progression of atherosclerosis: the atherosclerosis risk in communities (aric) study. JAMA 1998;279:119-24.

35 Dochi M, Sakata K, Oishi M, et al. Smoking as an independent risk factor for hypertension: a 14-year longitudinal study in male Japanese workers. Tohoku J Exp Med 2009;217:37-43.

36 Gu L, Pandey V, Geenen DL, et al. Cigarette smoke-induced left ventricular remodelling is associated with activation of mitogen-activated protein kinases. Eur J Heart Fail 2008;10:1057-64.

37 Quillen JE, Rossen JD, Oskarsson HJ, et al. Acute effect of cigarette smoking on the coronary circulation: constriction of epicardial and resistance vessels. J Am Coll Cardiol 1993;22:642-7.

38 Elihimas Júnior UF, Elihimas HC, Lemos VM, et al. Smoking as risk factor for chronic kidney disease: systematic review. J Bras Nefrol 2014;36:519-28.

39 Yamauchi T, Miyagawa S, Yoshikawa Y, et al. Risk index for postoperative acute kidney injury after valvular surgery using cardiopulmonary bypass. Ann Thorac Surg 2017:104:868-75

40 Castagno C, Varetto G, Quaglino S, et al. Acute kidney injury after open and endovascular elective repair for infrarenal abdominal aortic aneurysms. J Vasc Surg 2016;64:928-33. 